\title{
Effect of Plastic Anisotropy and Process Parameters on the Final Geometry of U-shaped Product in Cold Roll Forming
}

\section{Amin Poursafar}

Islamic Azad University Najafabad Branch

Saeid Saberi ( $\nabla$ saeid_saberi@yahoo.com )

Islamic Azad University Najafabad Branch

Rasoul Tarkesh

Islamic Azad University Najafabad Branch

Meisam Vahabi

Islamic Azad University Najafabad Branch

Javad Jafari Fesharaki

Islamic Azad University Najafabad Branch

\section{Original Article}

Keywords: cold roll forming, longitudinal bowing, anisotropy, U-shaped section

Posted Date: August 6th, 2021

DOI: https://doi.org/10.21203/rs.3.rs-717301/v1

License: (9) This work is licensed under a Creative Commons Attribution 4.0 International License. Read Full License 


\title{
Effect of plastic anisotropy and process parameters on the final geometry of U-shaped product in cold roll forming
}

\author{
Amin Poursafar ${ }^{1}$. Saeid Saberi ${ }^{2}$. Rasoul Tarkesh ${ }^{3}$. Meisam Vahabi ${ }^{4}$. Javad Jafari Fesharaki ${ }^{5}$
}

\begin{abstract}
Since the cold roll forming process is currently used in the production of different sections, it is necessary for manufacturers to further improve the quality of these products. Therefore, it is essential to study various factors influencing the production of these products in detail and provide effective solutions to reduce the factors causing defects in such products. This paper investigates the effect of plastic anisotropy and various factors such as strip thickness, the inter distance between stands, web width, and angle increment on the longitudinal bowing and then compares the results with the practical experiments. Accordingly, a model considering the effect of these parameters on the longitudinal bowing of the final section is considered with the accuracy of $88 \%$. The results show that strip thickness and the increment angle at each stand, and the web width have the most influence on the longitudinal bowing, while strip anisotropy and the inter distance has the least effect on bowing.
\end{abstract}

Keywords: cold roll forming, longitudinal bowing, anisotropy, U-shaped section

\section{Introduction}

Cold roll forming is a process involves several continuous and sequential metal forming steps, that each step approaching the final product by applying a certain amount of forming. Each stage of forming is performed at a specific forming stand with multiple rolls. Usually, the set consists of upper and lower rolls and if necessary, side rolls are used near the strip, which can improve the forming conditions. In this process, in certain cases, a series of side rolls are used in the distance between the main rolls. The strip thickness remains constant during the process which is one of the most important advantages of this process. This makes it possible to manufacture high-quality products that have a longitudinally uniform cross-section. One of the most important factors in the uniformity of the forming process is the application of the same power to the rolls of each stand. In this process, the velocity gradient is used to prevent strip wrinkling between the two stands. This incremental increase is along with the increase in roll diameter at each stand, relative to the previous one. In the case of low-thickness strips, a more gradual increase is required because as in high-thickness strips, bowing and wrinkling occur less frequently [1]. Generally the strip in a cold state is continuously formed into a profile with the desired cross-section through a series of rotating rolls, without noticeable change in thickness [2]. Figure 1 illustrates the cold roll forming machine; as can be seen, the longitudinal bowing perpendicular to the transverse axis of the cross-section web width causes bowing with the specified radius.

\footnotetext{
${ }^{1}$ amin.poursafar@smc.iaun.ac.ir, https://orcid.org/0000-0001-8794-4802.

${ }^{2}$ Corresponding author Email: saeid_saberi@yahoo.com, https://orcid.org/0000-0001-5005-9949 Department of Mechanical Engineering, Najafabad Branch, Islamic Azad University, Najafabad, Iran. Tel.: +31-42291111 


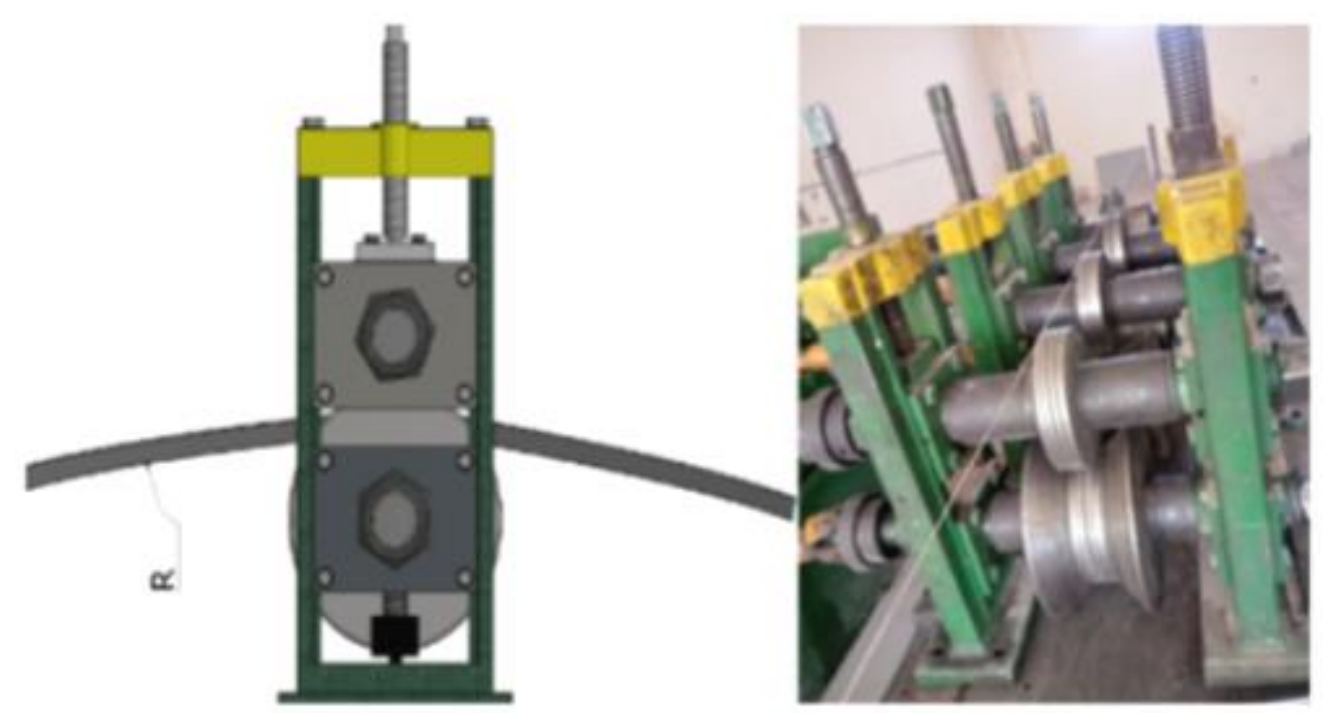

Figure 1 Cold roll forming machine and longitudinal Bowing defect

Ona showed that displacing stands at heights and applying straightener rolls at the end of the line can reduce the effect of longitudinal bowing [3]. Bhattacharyya and Smith investigated the effect of inter distance between forming stands on single stand formation and the results of their experimental and practical investigations showed the effects of strip thickness, angle and flange width on the longitudinal bowing of the channel [4]. In yet in another study, Bhattacharyya et al. investigated the effects of angle increment on longitudinal strains, and their results revealed that the influence of first and last stands angles [5]. Further, Duncan and Zhu investigated the parameters affecting the U-shaped and hat-shaped products in a four-stand process, revealing other destructive effects than transverse, longitudinal and shear strains [6]. Using a five-stand line and selecting the symmetric cross section, Sheu found the effects of the bend angle, speed line, friction coefficient, radius of roll at the bowing site and flange width experimentally, showing that speed line and bend angle at each stand had the greatest effect compared to other parameters studied [7]. Using the ABAQUS finite element software, Tehrani et al. Predicted localized edge bowing as a limiting factor in the formation of cold-roll forming of U-shaped cross-sections. Their simulations showed that the bend angle at the first stand should be less than a certain value to prevent localized bowing which occur at the next stands [8]. Shirani et al. studied the effect of different parameters of the cold roll forming on the preholes strip. In this study, uphill and downhill of rolls, angle increment and the inter distance were considered as the input variables and the amount of the ovality of holes after forming was taken as the output. Finally, strip thickness was introduced as the most significant parameter affecting the ovality of holes [9]. Shirani et al. also studied longitudinal bowing as the output, observing the greatest effect on it is bending angle at each stand. They also investigated the effects of strip thickness, flange width, flower pattern and the inter distance on product bowing and compared the practical test results with the simulation done by ABAQUS software. The results showed the direct effects of strip thickness, bend angle at each stand and flange width on the longitudinal bowing of the product[10]. Shirani et al. showed the effects of input parameters on the torsional torque of each stand. They showed that the increase in angle increment also raised the amount of torsional torque required; also, with increase in the thickness of the strip, the required torque was raised at each stand [11]. Lindgren used high strength steels in symmetrical sections and concluded that by increasing the deformation length, the longitudinal strain on the edge of the strip was reduced, ultimately decreasing the effect of longitudinal bowing(Lindgren, 2007). Salmani and Poursina used combination of regression method and artificial neural network for prediction of longitudinal bowing which is 
accrue in symmetrical channel section; they obtained the same results using both methods [13]. Bui et al. performed a simulation based on METAFOR code to simulate symmetrical U shaped section; they also found that the inter distance, speed line, mechanical properties and friction were effective on longitudinal strains [14]. Lindgren completed his research by developing a model based on full-factorial design in which the number of forming stands was taken as variable. He showed that the flange width and angle increment had significant effects on the deformation length. It was also revealed that the longitudinal strain was enhanced with increasing the strip thickness and reduced with decreasing the radius of bend rolls and yield strength[15]. Using 3D analysis, Zhang et al. investigated the finite components of the Ushaped channel cross-section using the ABAQUS software. They identified the important factors influencing the process. A set of experiments were designed to provide a statistical relationship based on the response surface method. Mathematical models were developed, and revealed the effect of the angle increment and the radius of rolls on the spring back. In the model created, the spring back was considered as the response and the longitudinal strains were taken as the model constraint. Finally, by developing quadratic models between the radius of bend and the spring back and optimizing it, they could reduce the number of forming stands[16]. Pouin et al. worked on the longitudinal bowing at the inter distance between the forming stands and their reduction. The results showed that the number of forming stands, the inter distance and strip thickness had the most influence on the longitudinal bowing[17]. Cha et al. conducted a study on longitudinal strains and twisting effects on asymmetric cross sections. In their research, they used a high-strength steel and their results showed that the longitudinal bowing and twisting could be reduced by applying additional pressure on the strip along the strip thickness[18]. Weibenga et al. Showed that the reduction of gap between rolls results a minimum value of longitudinal bowing defect [19]. Safdarian et al. studied the effect of angle increment, strip thickness, flange width, web width, the inter distance, speed line and friction coefficient on longitudinal bowing and strains. They showed that the maximum longitudinal strain would occur with increasing the angle increment and strip thickness. Moreover they reported that the speed line and friction coefficient between the rolls had no effect on the longitudinal bowing[20]. This research was aimed to characterize the effect of material properties and tool geometry on the longitudinal bowing of U-shaped product in cold roll forming.

\section{Materials and methods}

\subsection{Materials and product geometry}

Figure 2 shows the U-shaped cross section used in the present study. L represents the sample length, w denotes the web width, F refers to the flange width, $t$ represents the strip thickness, and $\mathrm{r}$ is the bend radius. 

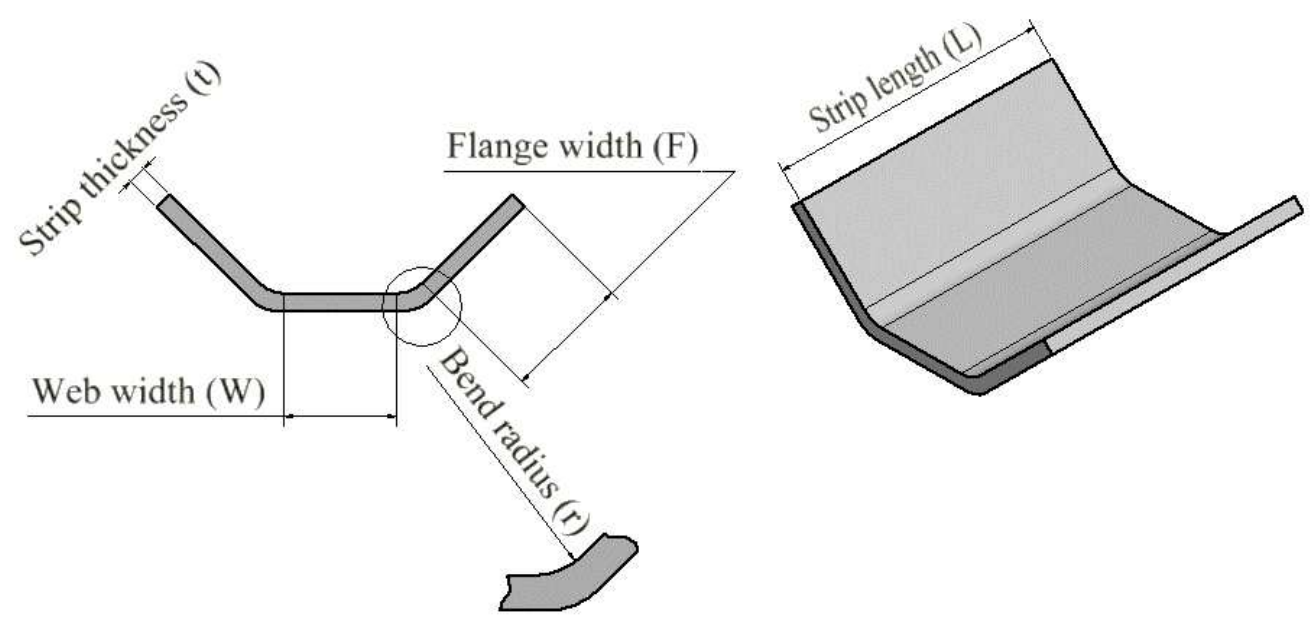

Figure 2 Characteristics of the symmetrical channel section

The samples length was $1000 \mathrm{~mm}$ and the strip used was DC03 (1.0347), which is common in the automotive industry. Figure 3 shows the stress-strain diagram of this strip; as can be seen, it does not have the same mechanical properties in the coil direction and vertical dimension. For this purpose, half of the samples tested were re-annealed in a suitable furnace to be made uniform in terms of mechanical properties. The mechanical properties of this type of steel are presented in Table 1.

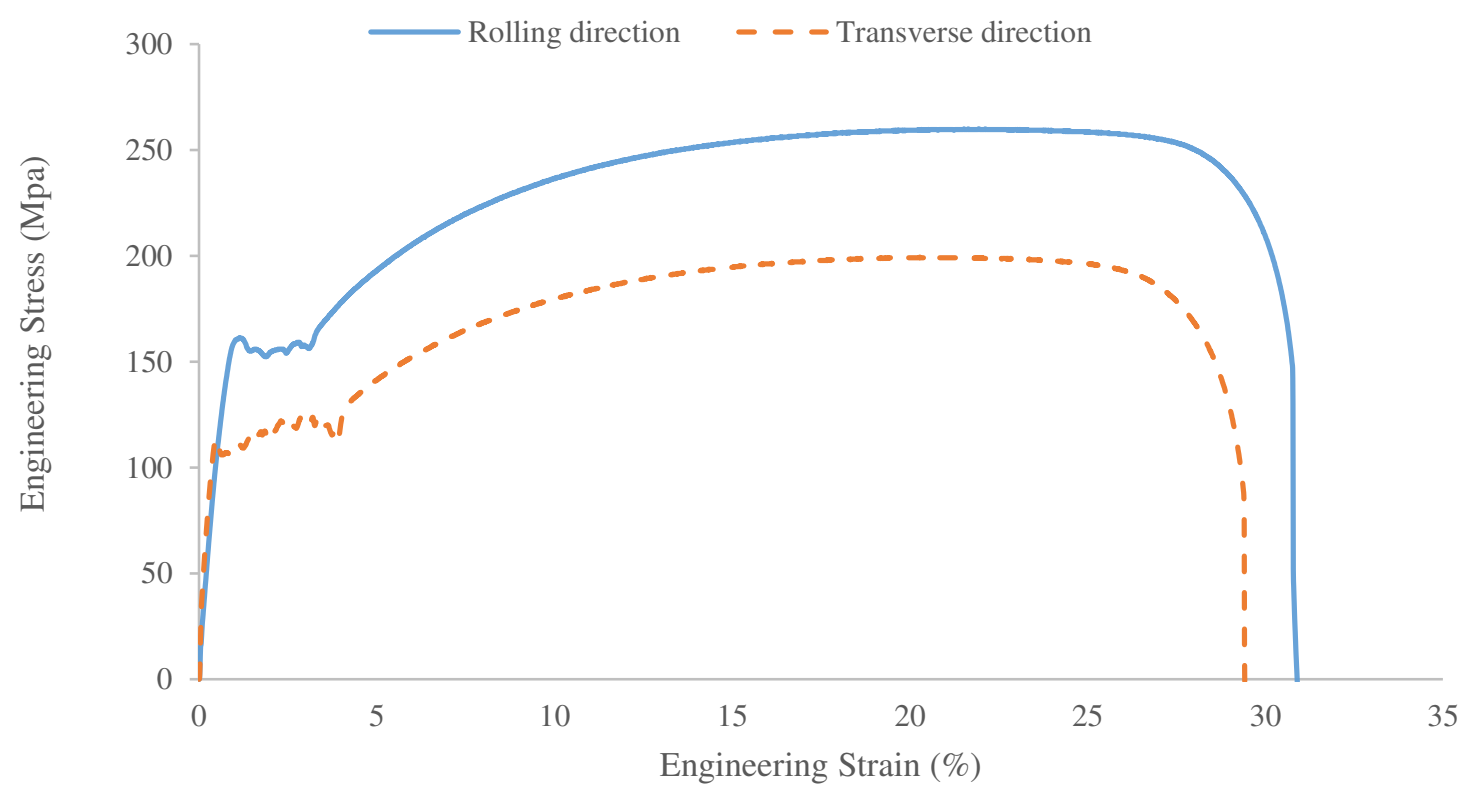

Figure 3 Stress-strain diagram for samples 


\begin{tabular}{lr}
\hline Young's modulus (Gpa) & 207 \\
Poisson's ratio & 0.3 \\
Elastic limit & 0.002 \\
Density $\left(\mathrm{Kg} / \mathrm{m}^{3}\right)$ & 7800 \\
\hline
\end{tabular}

\subsection{Effective parameters}

The parameters studied are presented in Table 2.

Table 2 Input parameters

\begin{tabular}{cccc}
\hline Parameter & Unit & \multicolumn{2}{c}{ levels } \\
\hline $\begin{array}{c}\text { Bend angle } \\
\text { increment (B.I) }\end{array}$ & Degree & $0,22.5,45$ & $0,15,30,45$ \\
Web width (w) & $\mathrm{mm}$ & 20 & 40 \\
Strip thickness (t) & $\mathrm{mm}$ & 2 & 2.5 \\
Inter distance (d) & $\mathrm{mm}$ & 300 & 500 \\
Structure $(\mathrm{H})$ & - & Normal & Annealed \\
\hline
\end{tabular}

Factors considered as those affecting longitudinal bowing in the previous studies have been introduced as the influential factors affecting the longitudinal strain. Also, the structure of the tested samples (anisotropy) is investigated as a new factor. As mentioned in Table 2, the angle increment or flow pattern is considered to be in two-stand and three-stand patterns. The crosssection web width was 20 and $40 \mathrm{~mm}$, the strip thickness was 2 and $2.5 \mathrm{~mm}$ and inter distance was 300 and $500 \mathrm{~mm}$, respectively. The final structure of the samples was analyzed under normal and annealed conditions. In order to increase the accuracy of the tests and the results for the practical tests, three samples were prepared for each test and the mean of the results was analyzed. The complete data is given in Table 3.

Table 3 complete data

\begin{tabular}{cccccccc}
\hline test no & Anisotropy & $\begin{array}{c}\text { Thickness } \\
(\mathrm{mm})\end{array}$ & $\begin{array}{c}\text { Web } \\
\text { width } \\
(\mathrm{mm})\end{array}$ & $\begin{array}{c}\text { Angle } \\
\text { increment } \\
(\text { degree })\end{array}$ & $\begin{array}{c}\text { Inter } \\
\text { distance } \\
(\mathrm{mm})\end{array}$ & $\begin{array}{c}\text { Simulation } \\
\text { Bowing } \\
(\mathrm{mm})\end{array}$ & $\begin{array}{c}\text { Experimental } \\
\text { Bowing } \\
(\mathrm{mm})\end{array}$ \\
\hline \hline 1 & Annealed & 2 & 20 & 22.5 & 500 & 5.619 & 9.37 \\
2 & Annealed & 2.5 & 40 & 22.5 & 500 & 7.226 & 10.04 \\
3 & Normal & 2.5 & 20 & 15 & 500 & 25.626 & 12.26 \\
4 & Normal & 2 & 20 & 15 & 300 & 7.404 & 7.50 \\
5 & Normal & 2 & 20 & 15 & 500 & 1.969 & 5.24 \\
6 & Annealed & 2.5 & 20 & 15 & 500 & 23.605 & 32.59 \\
7 & Normal & 2 & 20 & 22.5 & 300 & 8.872 & 20.12 \\
8 & Annealed & 2.5 & 40 & 15 & 300 & 24.843 & 22.60 \\
9 & Annealed & 2.5 & 20 & 15 & 300 & 4.087 & 7.39
\end{tabular}




\begin{tabular}{|c|c|c|c|c|c|c|c|}
\hline 10 & Normal & 2 & 40 & 22.5 & 500 & 2.099 & 5.56 \\
\hline 11 & Annealed & 2 & 40 & 15 & 300 & 12.419 & 15.67 \\
\hline 12 & Annealed & 2 & 40 & 15 & 500 & 10.74 & 15.23 \\
\hline 13 & Normal & 2.5 & 40 & 22.5 & 300 & 12.882 & 13.42 \\
\hline 14 & Normal & 2.5 & 40 & 15 & 300 & 28.856 & 42.08 \\
\hline 15 & Normal & 2.5 & 20 & 15 & 300 & 5.529 & 22.30 \\
\hline 16 & Annealed & 2.5 & 40 & 15 & 500 & 33.142 & 42.65 \\
\hline 17 & Annealed & 2 & 20 & 15 & 300 & 10.664 & 19.76 \\
\hline 18 & Annealed & 2.5 & 20 & 22.5 & 500 & 13.824 & 16.80 \\
\hline 19 & Annealed & 2 & 40 & 22.5 & 300 & 1.886 & 6.89 \\
\hline 20 & Normal & 2 & 40 & 22.5 & 300 & 1.89 & 6.58 \\
\hline 21 & Normal & 2 & 20 & 22.5 & 500 & 4.393 & 8.35 \\
\hline 22 & Annealed & 2 & 20 & 22.5 & 300 & 10.895 & 16.32 \\
\hline 23 & Normal & 2.5 & 20 & 22.5 & 500 & 14.72 & 16.68 \\
\hline 24 & Annealed & 2.5 & 40 & 22.5 & 300 & 9.182 & 7.65 \\
\hline 25 & Annealed & 2 & 40 & 22.5 & 500 & 2.134 & 2.65 \\
\hline 26 & Annealed & 2 & 20 & 15 & 500 & 3.559 & 6.11 \\
\hline 27 & Normal & 2 & 40 & 15 & 300 & 11.336 & 16.55 \\
\hline 28 & Normal & 2.5 & 40 & 15 & 500 & 35.856 & 23.56 \\
\hline 29 & Annealed & 2.5 & 20 & 22.5 & 300 & 13.254 & 19.20 \\
\hline 30 & Normal & 2 & 40 & 15 & 500 & 11.456 & 12.03 \\
\hline 31 & Normal & 2.5 & 20 & 22.5 & 300 & 14.617 & 16.65 \\
\hline 32 & Normal & 2.5 & 40 & 22.5 & 500 & 7.29 & 12.68 \\
\hline
\end{tabular}

\subsection{Forming machine}

The investigated apparatus consists of seven forming stands with a 45 kilo-Watt motor supplier. All stand gearboxes were parallel coupled. One of the special features of this device was the ability to move the stands in their length and height directions. In addition, the device was equipped with an electronic speed control system, so that the speed line could be adjusted precisely. The investigated machine consisted of three units, one for the stands assembly, the second one for the installation of gearboxes, and the third one for the installation of the motor. In general, the length of the forming line in this machine was 7 meter and the level of the table was $55 \mathrm{~cm}$ from the floor. Also, to better control the strip during the process and to prevent its movement in the traverse direction, a guide system was also designed and manufactured to better control the strip during the process and to prevent the transverse movement; its role is to prevent the strip from moving in the transverse direction and maintain its alignment with the forming line. Figure 4 shows the various components of this machine. 


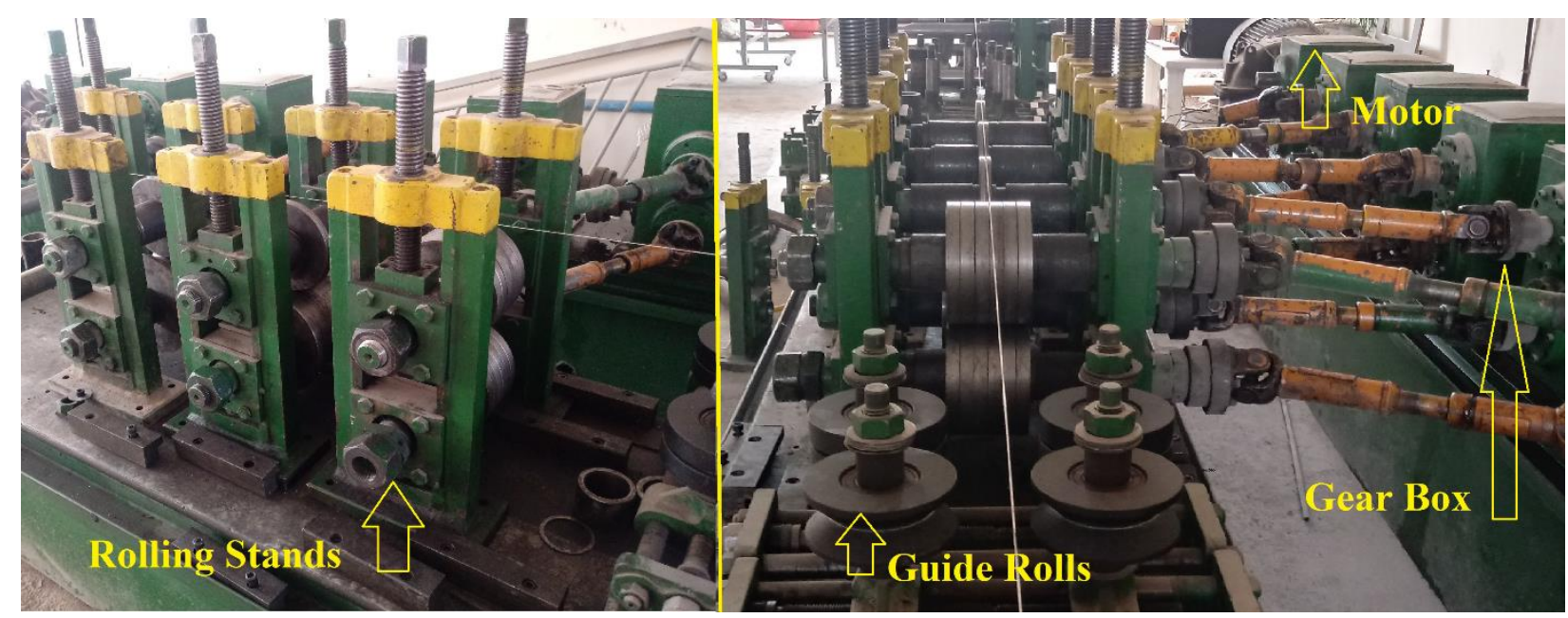

Figure 4 Forming line and guide system

The speed of sheet was set to be $22.5 \mathrm{~mm} / \mathrm{s}$ to prevent vibration during forming process. Forming rolls were used as flat disc (B) and forming roll (A), and different web widths could be obtained by combining flat disc and forming roll. Figure 5 shows the combination of forming rolls.

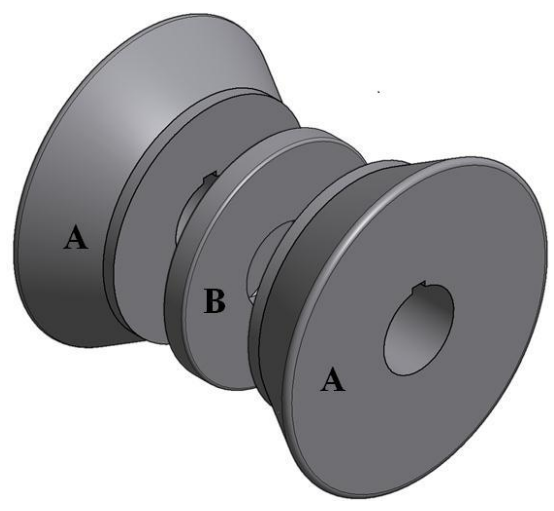

Figure 5 Three pieces of forming roll

\subsection{Measurement of the effect of longitudinal bowing}

To assess the longitudinal bowing, the image processing technique and the $\mathrm{Ni}$-vision software were used. For this purpose, a Nikon-coolpixL110 camera with a resolution of 12 megapixels was used and the samples were photographed according to Figure 6; the software measured the difference between the edges of the sample in the middle of strip as a criterion for longitudinal bowing. The gauge block was used throughout the imaging process to calibrate the software and convert the pixels to millimeters. This measurement was done in three steps on both sides of the piece and the mean of the obtained numbers was considered as the criterion of longitudinal bowing. 


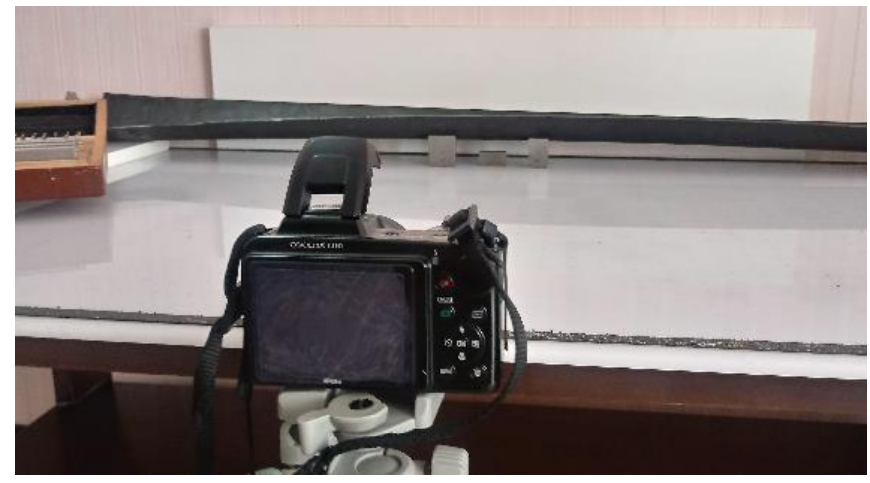

Figure 6 Image processing apparatus

\section{Process simulation}

The process simulation was done in ABAQUS explicit 2018 software; the model developed in accordance with Figure 7. This model consisted of strip, forming rolls with a geometrical shape similar to that used in the experiments. The rolls were of the analytical rigid type and the strip was a shell type model with shell element, S4R and the model was designed symmetrical with mirror plane Y axe[8].

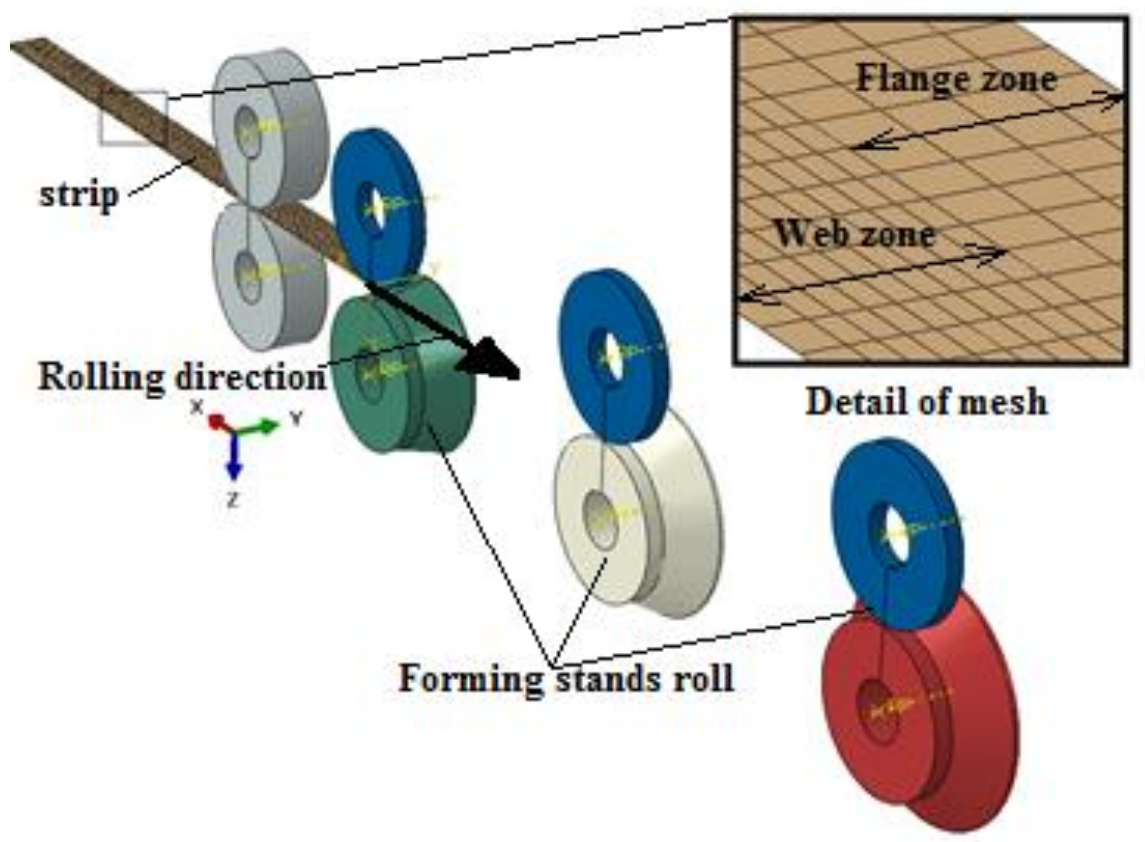

Figure 7 the model and mesh of strip

The longitudinal strain of all samples was measured from a distance of $500 \mathrm{~mm}$ from the beginning of the specimen and the effect of longitudinal bowing was investigated by creating a path in the edge of the specimens. These details are shown in Figure 8. 


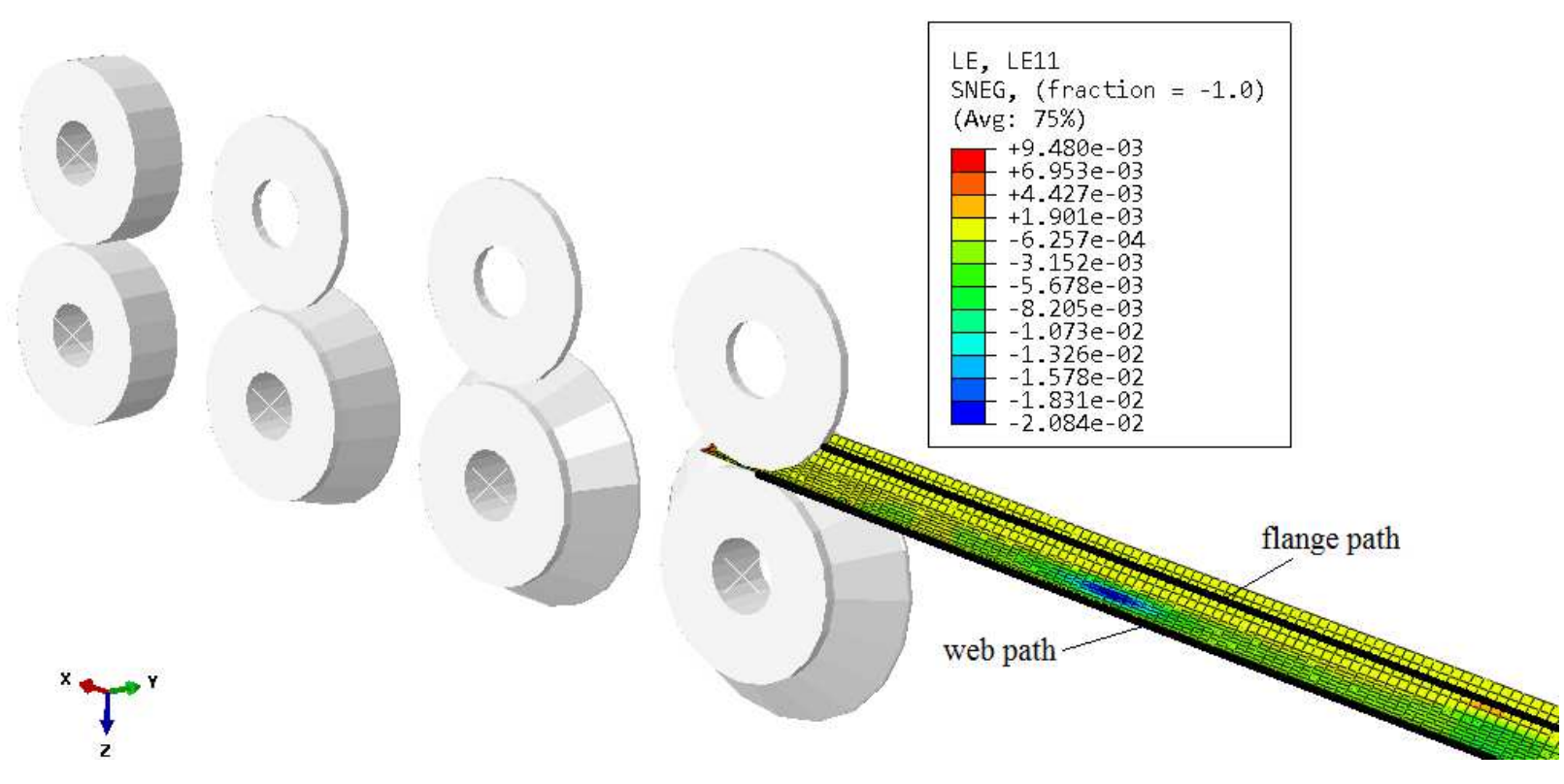

Figure 8 Distribution of the longitudinal strain after the forming process

In order to obtain the best mesh in terms of size, the mesh convergence was determined by considering the longitudinal bowing of what was obtained in the practical experiments; according to the analysis time of the software, the optimal meshing was obtained with two different sizes at the flange and web, respectively, as can be seen in Figure 7. Due to the fact that the decrease in mesh size at flange zone does not show any effect on the longitudinal bowing, a size ratio of 0.5 was chosen for the strip web. The friction coefficient between the rolls was assumed to be 0.2 , as previously obtained. Due to the roll forming process, the strip thickness remains constant, so the gap size in the model created at all stands was assumed to be equal to the strip thickness. The model has been symmetrically designed (Y symmetrical) to create the guide system and to prevent strips slipping in the transverse direction. Strip modeling was considered for the non-homogeneous state considering the anisotropy properties according to Hill 48 criterion and R-value constants in plastic properties. Since sheet metal is influenced by rolling conditions when manufactured and also mechanical properties of rolled sheets vary from each direction (with respect to rolling direction) to another direction, Hill introduced a yield criterion considering anisotropy of the sheet material.[21].

$$
2 f=F\left(\sigma_{22}-\sigma_{33}\right)^{2}+G\left(\sigma_{33}-\sigma_{11}\right)^{2}+H\left(\sigma_{11}-\sigma_{22}\right)^{2}+2 L{\sigma_{23}}^{2}+2 M{\sigma_{31}}^{2}+2 N{\sigma_{12}}^{2}
$$

In Equation 1, $\mathrm{f}$ is the yield function and F, G, H, L, M and $\mathrm{N}$ denote the material constants and are obtained from anisotropy coefficients deduced from uni-axial tensile test while $\mathrm{x}, \mathrm{y}$ and $\mathrm{z}$ are the anisotropy axes. Material constants can be expressed in terms of six yield stress ratios $r_{11}, r_{22}, r_{33}, r_{12}, r_{13}$ and $r_{23}$ according to Equations (2) and (3). Because of plain stress condition the $\mathrm{L}$ and $\mathrm{M}$ constant eliminated from Equation 1.

$$
\begin{aligned}
& F=\frac{1}{2}\left(\frac{1}{r_{22}^{2}}+\frac{1}{r_{33}^{2}}-\frac{1}{r_{11}^{2}}\right) \\
& G=\frac{1}{2}\left(\frac{1}{r_{33}^{2}}+\frac{1}{r_{11}^{2}}-\frac{1}{r_{22}^{2}}\right) \\
& H=\frac{1}{2}\left(\frac{1}{r_{11^{2}}{ }^{2}}+\frac{1}{r_{22}{ }^{2}}-\frac{1}{r_{33^{2}}}\right)
\end{aligned}
$$




$$
\begin{aligned}
& N=\frac{3}{2 r_{12}^{2}} \\
& r_{11}=r_{13}=r_{23}=1 \\
& r_{22}=\sqrt{\frac{r_{90}\left(r_{0}+1\right)}{r_{0}\left(r_{90}+1\right)}} \\
& r_{33}=\sqrt{\frac{r_{90}\left(r_{0}+1\right)}{\left(r_{90}+r_{0}\right)}} \\
& r_{12}=\sqrt{\frac{3 r_{90}\left(r_{0}+1\right)}{\left(2 r_{45}+1\right)\left(r_{90}+r_{0}\right)}}
\end{aligned}
$$

In order to calculate the required coefficients, the tensile test of the specimens was performed using the Zwic Roell Z400 and the relevant coefficients were calculated using the existing equations 2 and 3, as shown in Table 4. The plastic properties of the strip were obtained from the tensile test and then were given to the ABAQUS software.

Table 4 Hill 48 coefficient and $R$ value

\begin{tabular}{cccccccccc}
\hline \multicolumn{1}{c}{} & \multicolumn{3}{c}{ R values } & \multicolumn{3}{c}{ Hill coefficient } \\
\hline \hline R11 & R13 & R23 & R22 & R33 & R12 & F & G & H & N \\
\hline 1 & 1 & 1 & 1.027 & 1.294 & 5.113 & 0.272 & 0.325 & 0.675 & 0.0574 \\
\hline
\end{tabular}

\section{Results}

The effects of different inputs on the longitudinal bowing are analyzed separately and the mathematical model is obtained by considering all effects. Also, the double effects are obtained by the full factorial experiment design. By considering the simulation and experimental results, it can be seen that the results are robust.

\subsection{Analysis of variance}

The model is obtained using the design expert software and in this model the effects of all inputs and also double effects of these parameters are considered. These effects are presented in Table 2.

Table 5 shows the Variance Analysis of the model. Obviously, if F-Value is a large number and the R-Square number is close to 1 , then the best model accuracy can be reached. Considering Table 5 and Table 6, it can be seen that the simplest model (modified two factor model) has acceptable results.

Table 5 ANOVA table for longitudinal bowing

\begin{tabular}{cccccc}
\hline Source & Sum of square & $\begin{array}{c}\text { Degree of } \\
\text { freedom }\end{array}$ & Mean square & F-value & $\begin{array}{c}\text { P-value } \\
\text { Prob>F }\end{array}$ \\
\hline \hline Model & 2359.22 & 11 & 214.47 & 13.83 & $<0.0001$ \\
\hline
\end{tabular}




\begin{tabular}{|c|c|c|c|c|c|}
\hline A-Annealing & 1.86 & 1 & 1.86 & 0.12 & 0.7327 \\
\hline $\begin{array}{l}\text { B-strip } \\
\text { thickness }\end{array}$ & 873.66 & 1 & 873.66 & 56.33 & $<0.0001$ \\
\hline C- Web width & 62.16 & 1 & 62.16 & 4.01 & 0.0590 \\
\hline $\begin{array}{l}\text { D-Angle } \\
\text { increment }\end{array}$ & 452.31 & 1 & 452.31 & 29.16 & $<0.0001$ \\
\hline E-Inter distance & 18.98 & 1 & 18.98 & 1.22 & 0.2818 \\
\hline $\begin{array}{l}\text { Annealing-strip } \\
\text { thickness }\end{array}$ & 19.08 & 1 & 19.08 & 1.23 & 0.2805 \\
\hline $\begin{array}{l}\text { Strip thickness - } \\
\text { web width }\end{array}$ & 58.94 & 1 & 58.94 & 3.80 & 0.0654 \\
\hline $\begin{array}{l}\text { Strip thickness- } \\
\text { Angle } \\
\text { increment }\end{array}$ & 100.78 & 1 & 100.78 & 6.5 & 0.0191 \\
\hline $\begin{array}{l}\text { Strip thickness- } \\
\text { inter distance }\end{array}$ & 159.47 & 1 & 159.47 & 10.28 & 0.0044 \\
\hline $\begin{array}{l}\text { Web width- } \\
\text { angle increment }\end{array}$ & 510.48 & 1 & 510.48 & 32.91 & $<0.0001$ \\
\hline $\begin{array}{c}\text { Angle } \\
\text { increment- inter } \\
\text { distance }\end{array}$ & 101.49 & 1 & 101.49 & 6.54 & 0.0188 \\
\hline Residual & 310.21 & 20 & 15.51 & - & - \\
\hline Cor total & 2669.43 & 31 & - & - & - \\
\hline
\end{tabular}

Table 6 Fitted model values

\begin{tabular}{ccccc}
\hline Source & Std. deviation & $\begin{array}{c}\text { R-Squared } \\
\text { (adjusted) }\end{array}$ & $\begin{array}{c}\text { R-Squared } \\
\text { (predicted) }\end{array}$ & F-value \\
\hline \hline Two-factor model & 3.94 & 0.8838 & 0.8513 & 13.83 \\
\hline
\end{tabular}

Figure 9, shows the accuracy of the model by comparing the actual and estimated values. The scattered data points around the centerline prove the accuracy of this model. 


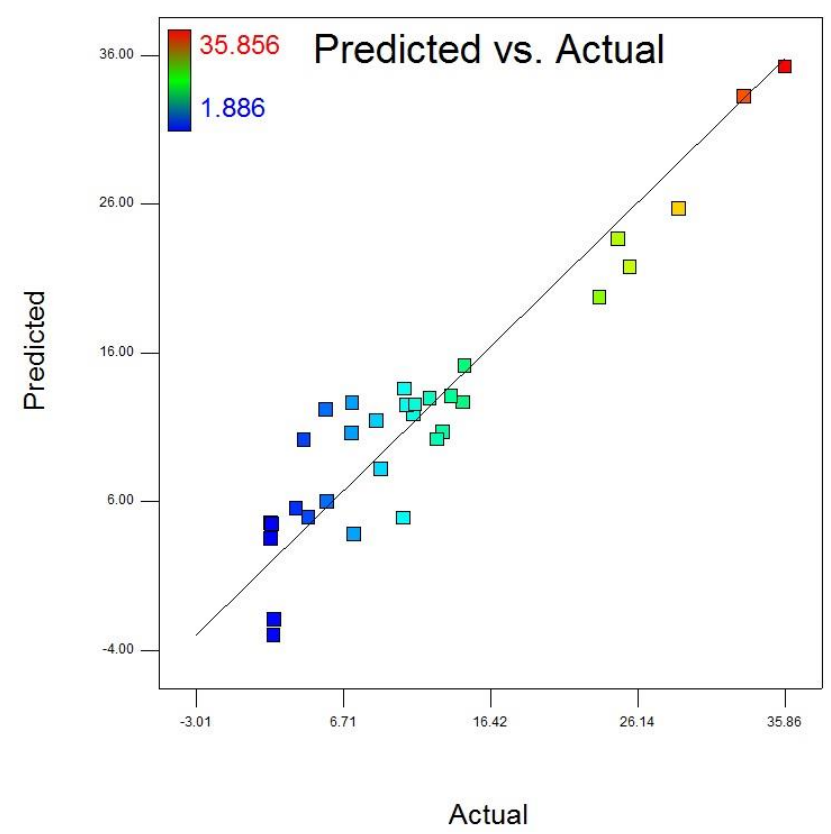

Figure 9 Comparison of the predicted and actual values in the model

Figure 10 shows the comparison between different fitted model values. The models with four and five factor were not fitted completely, so the data were not appeared in this figure.

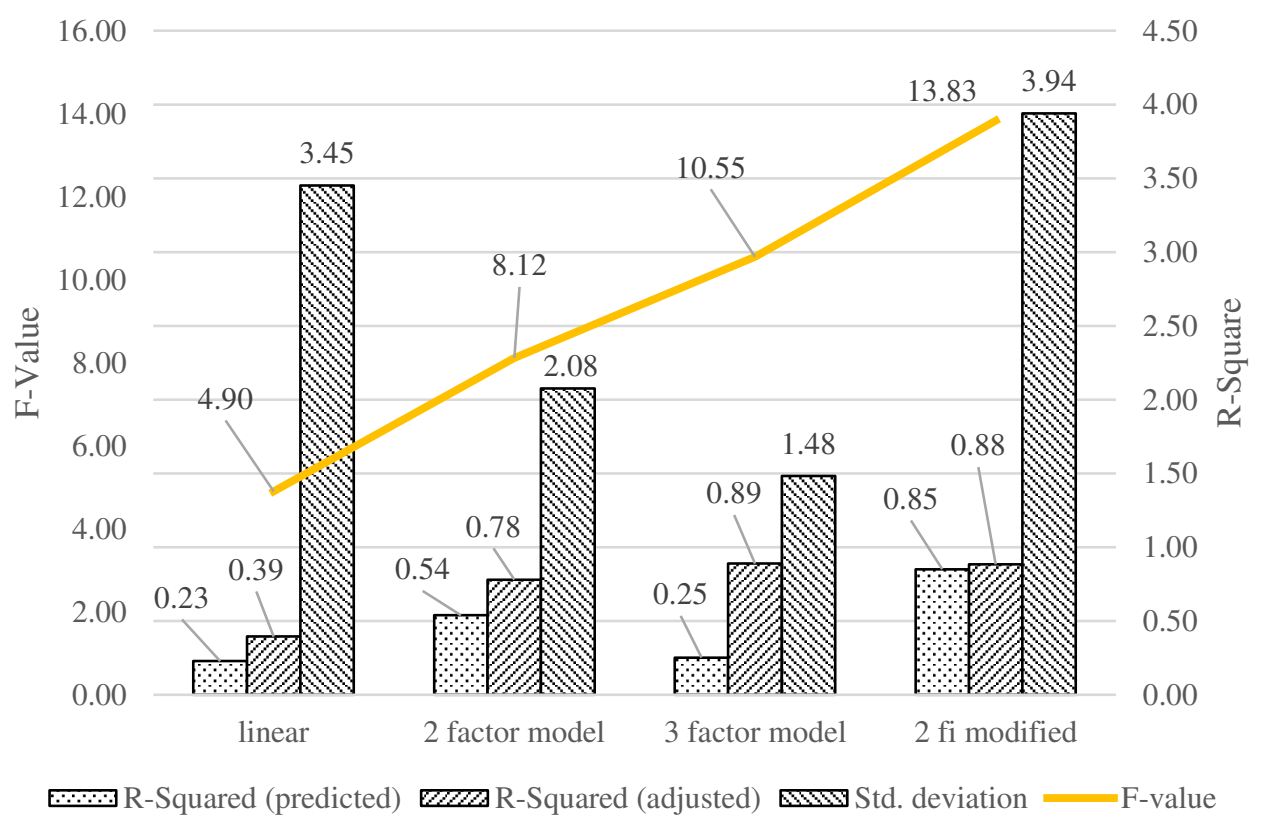

Figure 10 fitted model value comparison

\subsection{Longitudinal strain distribution}

Longitudinal bowing is defined as the product of the difference between the longitudinal strains at the flange and web[20]. The difference is considerable in Figure 11 and Figure 12. 


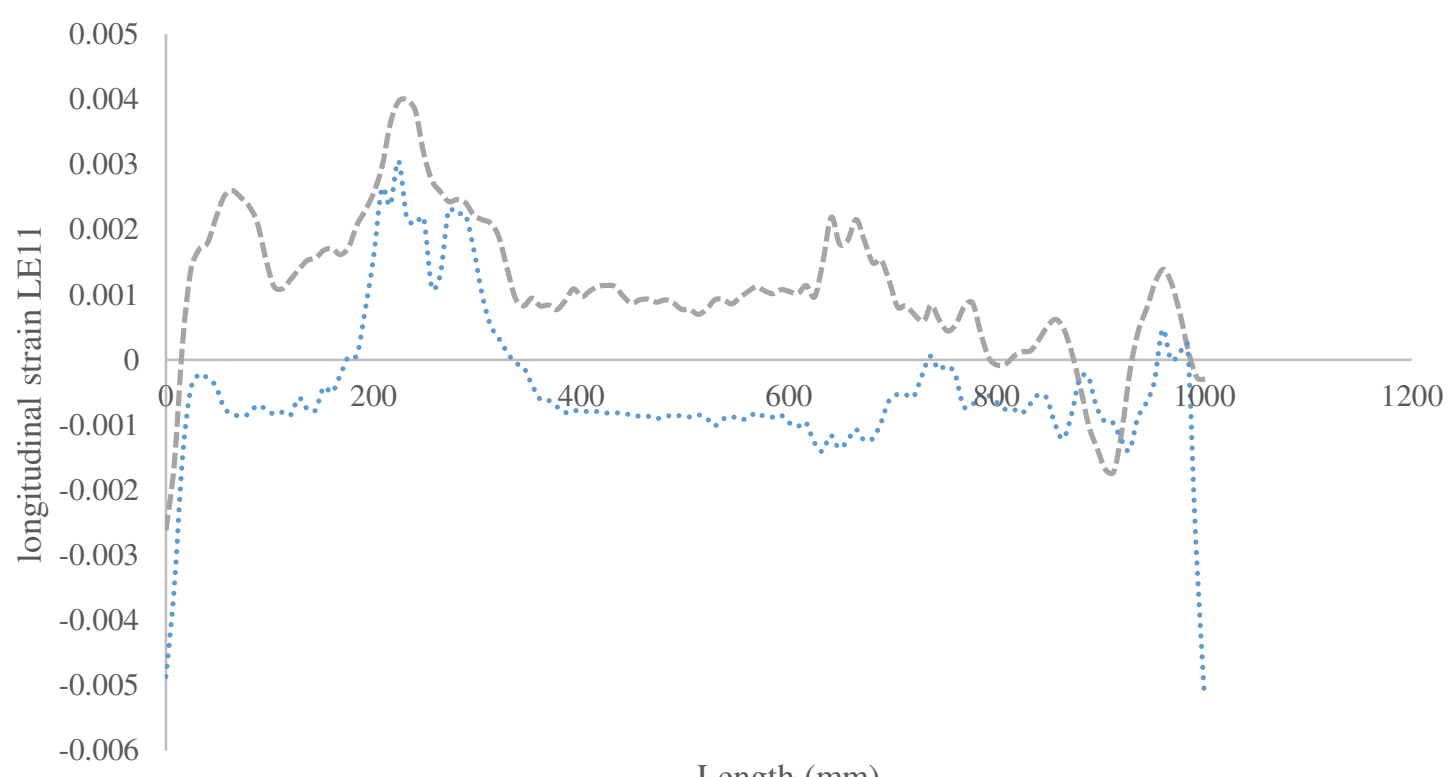

Length (mm)

=---= flange strain 2 stand $\quad \cdots \ldots . .$. web strain 2 stand

Figure 11 Longitudinal strain in web and flange zones in 22.5 degree angle increments

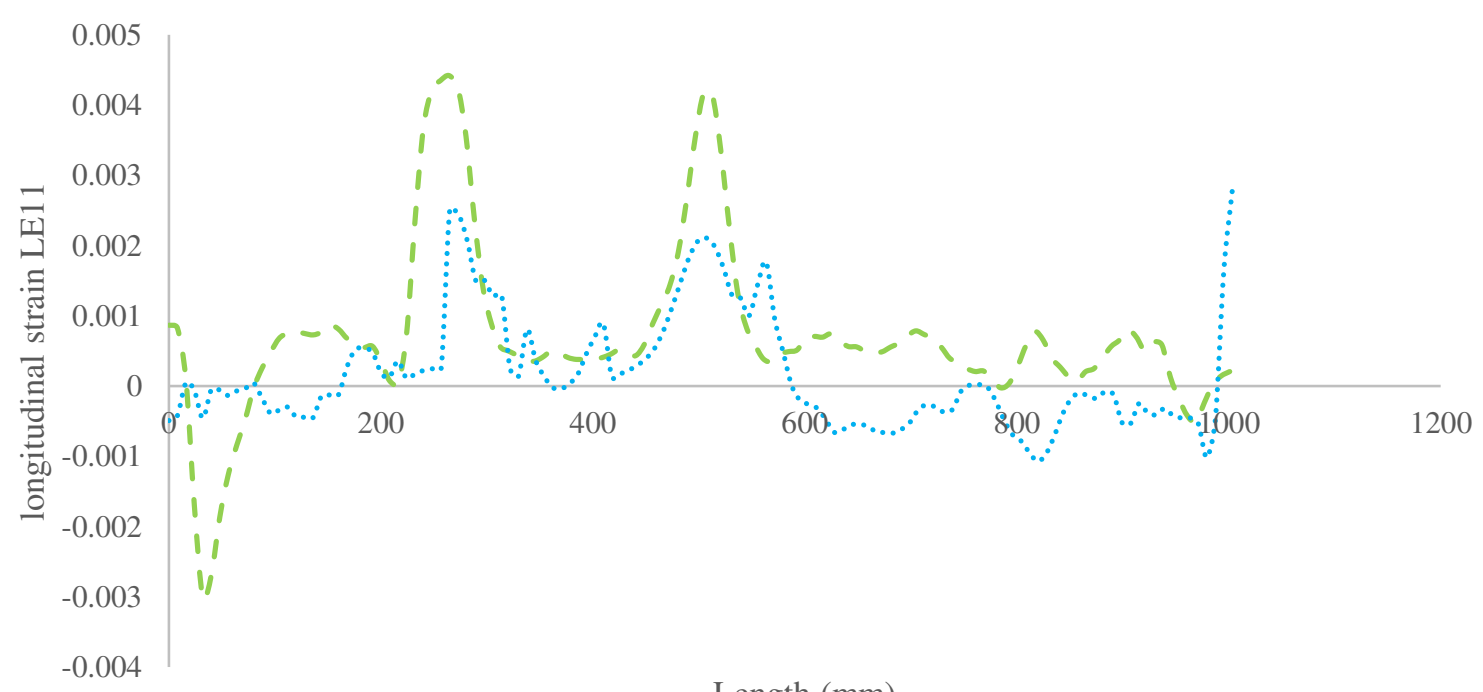

Length (mm)

- - - Flange strain 3 stand $\quad \ldots . . . .$. Web strain 3 stand

Figure 12 Longitudinal strain in web and flange zones in 15 degree angle increments

\subsection{Effect of strip thickness and flange width on longitudinal bowing}

Figure 13 shows the influence of strip thickness and flange width on the longitudinal bowing. An increase in strip thickness was resulted the increasing of longitudinal bowing. Based on the Equation 4, the longitudinal bowing was intensified by decreasing the crosssection flange width[22].

$L=\sqrt{\frac{8 a^{3} \theta}{3 t}}$ 
For constant values of the bending angle $(\theta)$ and the flange width (a), the required length for the process $(\mathrm{L})$ is decreased with the increasing of plate thickness. The required length of the strip for the rolling process (L), considering the constant values of the bending angle $(\theta)$ and the flange width (a), reduction of forming length increases the strip thickness ( $t$ ). The longitudinal flange strains were also increased, while longitudinal web strain did not change, which resulted increasing the longitudinal bowing.

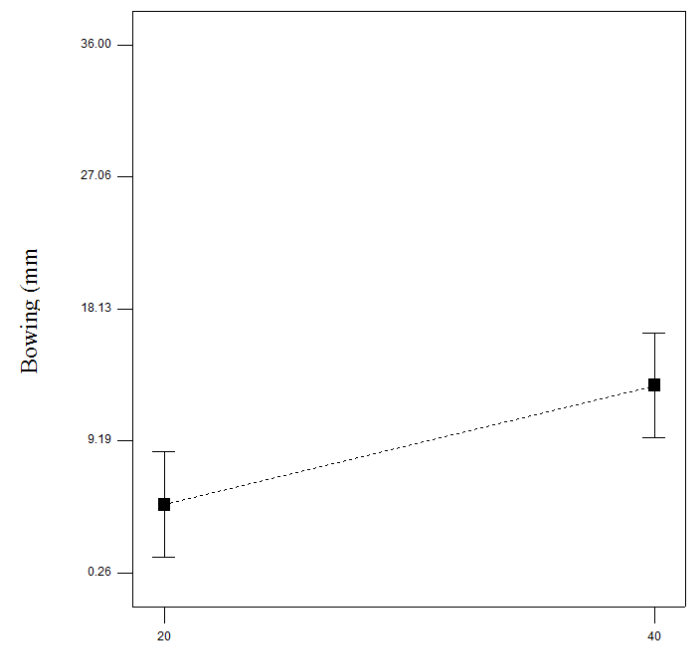

flange width $(\mathrm{mm})$

Figure 13 a) Effect of flange width on bowing

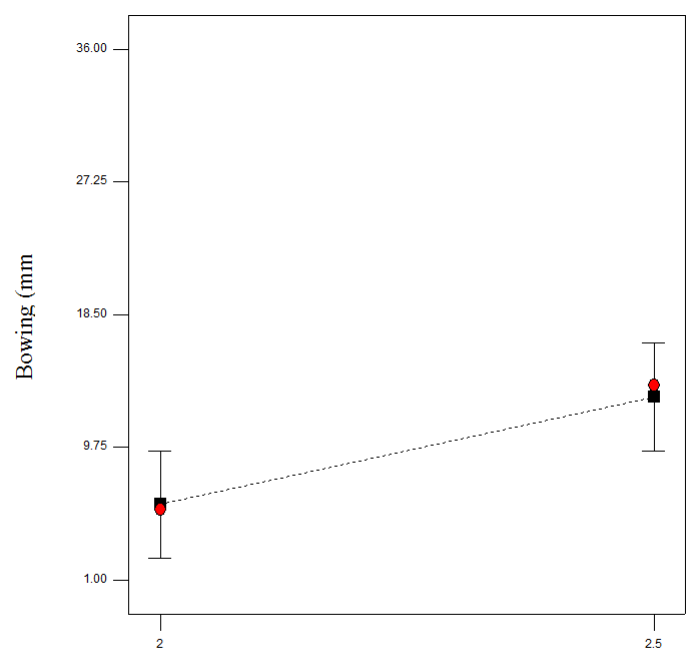

Strip thickness (mm)

b) Effect of strip thickness on bowing

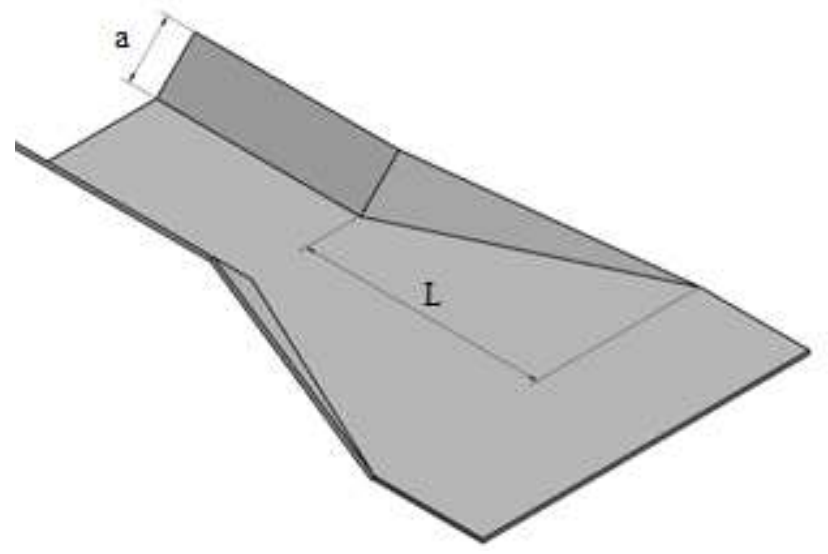

Figure 14 forming length

In other words, strip formation is possible in less time (see Figure 14 and Figure 15 and Figure 16). It can be seen that the longitudinal flange strains were also increased, while longitudinal web strain did not change, which raised the longitudinal bowing. 


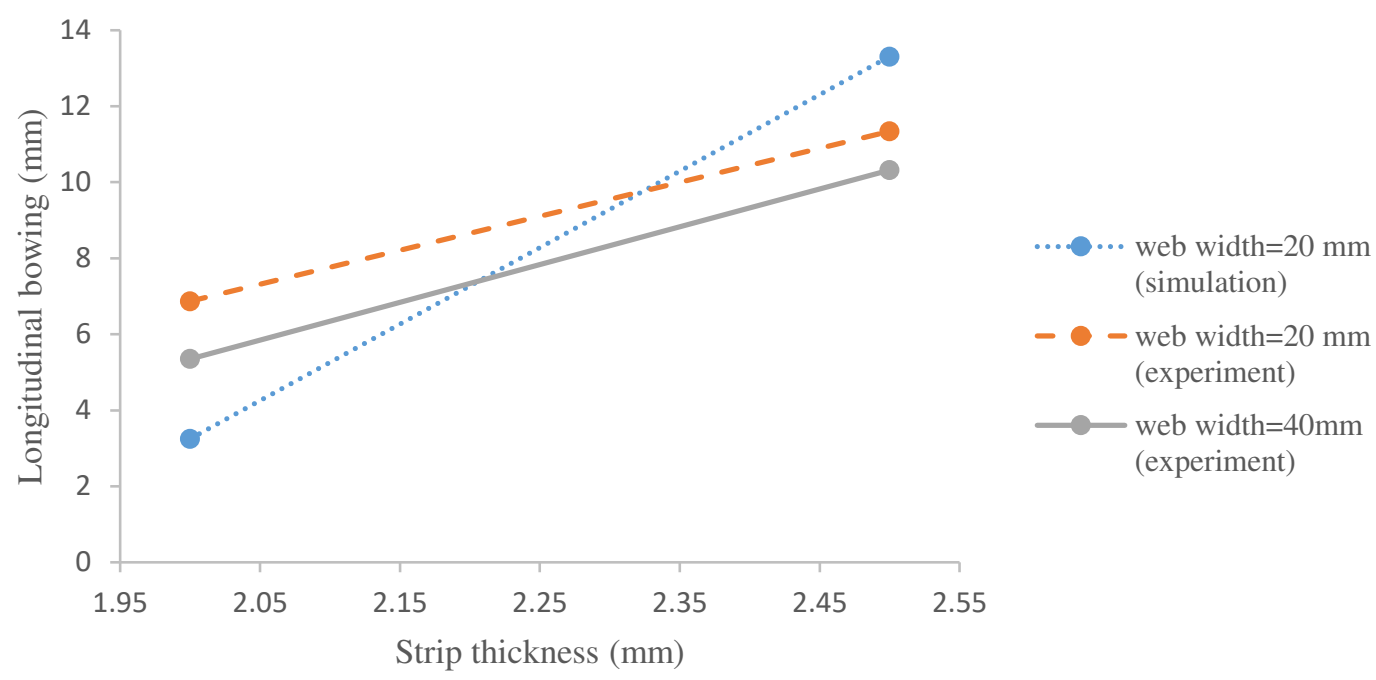

Figure 15 Effect of strip thickness on bowing

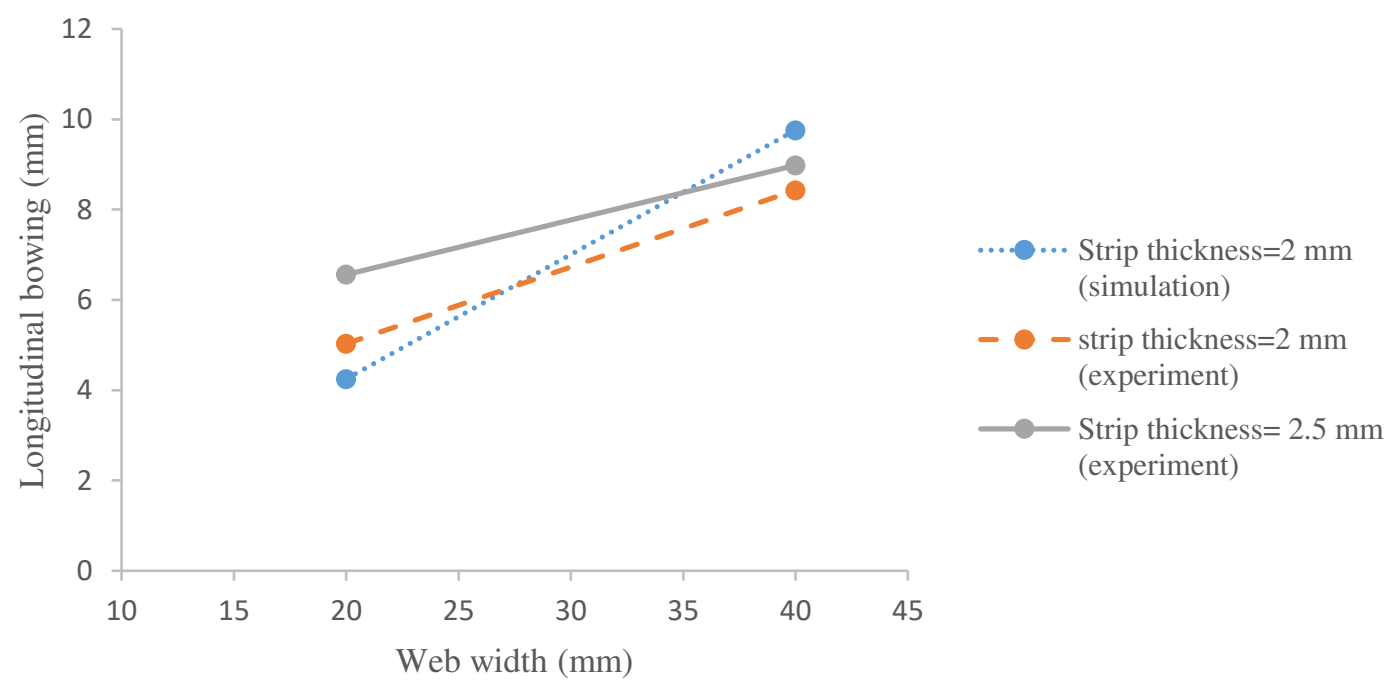

Figure 16 Effect of web width on bowing

\subsection{Effect of angle increment on Longitudinal Bowing}

As shown in Figure 17, the amount of longitudinal bowing was decreased with increasing the number of forming stands or with decreasing the angle increment at each stand. It could be seen that this decrease was intensified with the decrease of the web width. 


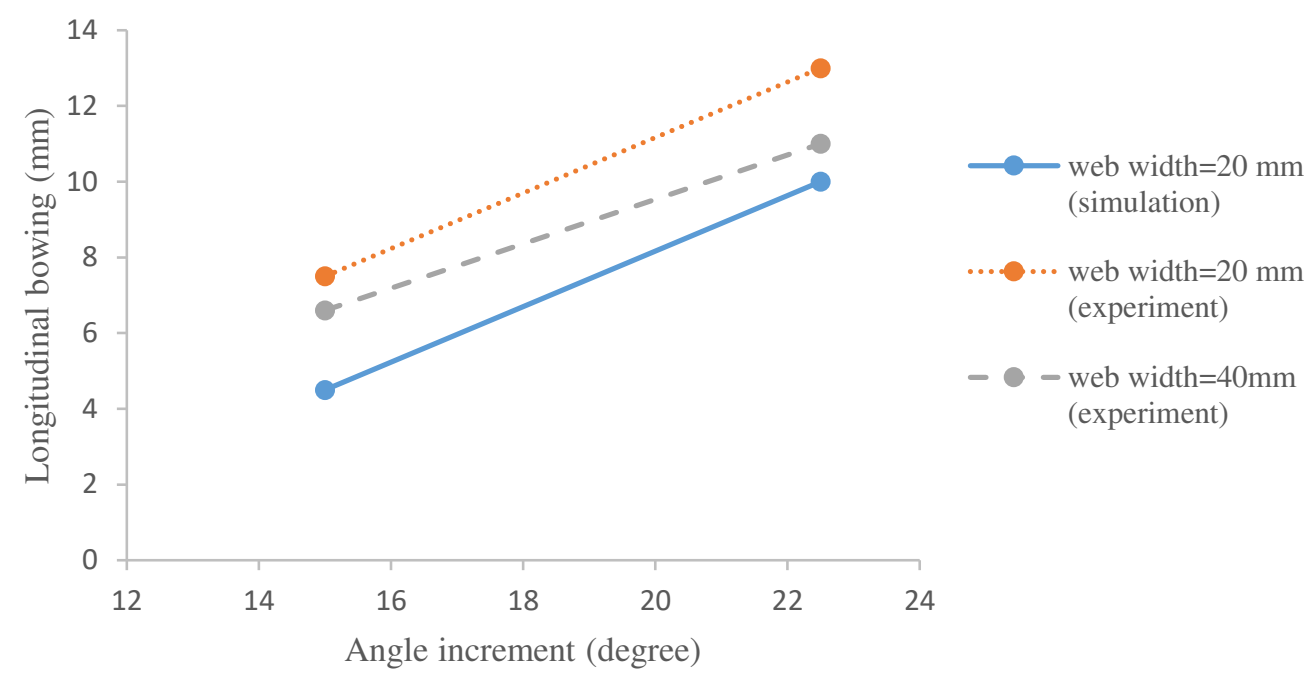

Figure 17 Effect of Angle increment on bowing

\subsection{The effect of plastic anisotropy on longitudinal bowing}

Regarding Figure 18, it can be seen that both experiments and simulations prove that the plastic anisotropy on the longitudinal bowing is tiny.

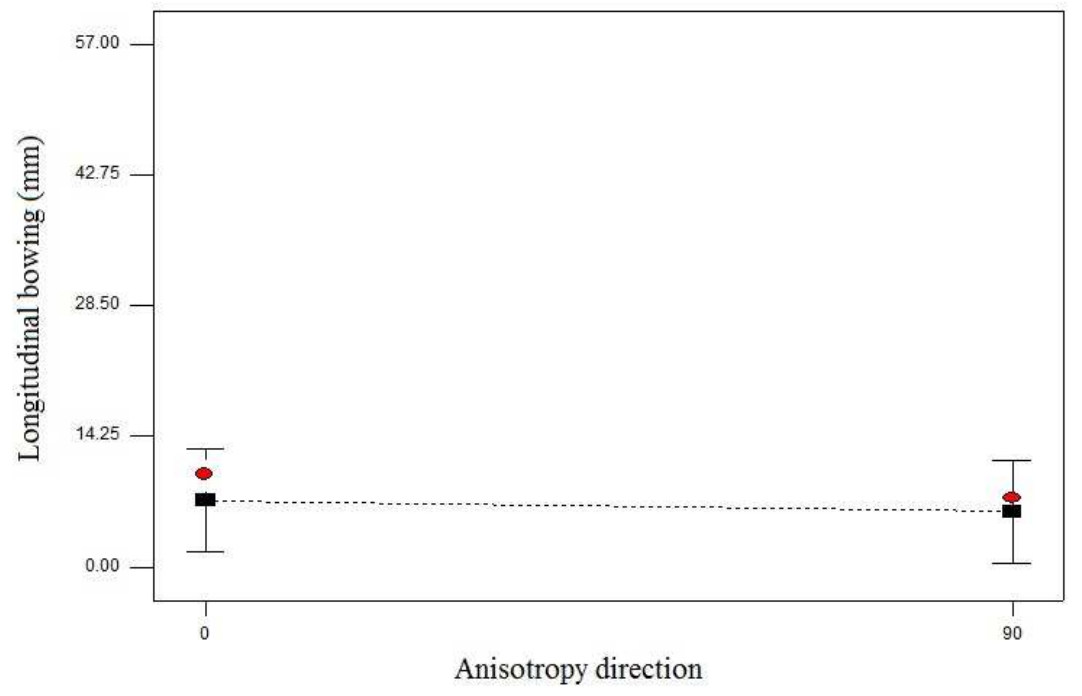

Figure 18 Effect of plastic anisotropy on bowing

\subsection{The effect of inter distance on longitudinal bowing}

Figure 19 shows the effect of inter distance on the longitudinal bowing. Based on the results, as the inter distance is increased, the longitudinal bowing is decreased. Also it can be seen that with increasing the inter distance, the longitudinal bowing is reduced. On the other hand, by increasing the number of forming stands and decreasing the angle increment, longitudinal bowing can be reduced. The distribution of strains in the web width have not shown a significant change[23]. It should be noted that by decreasing the differences of strains between the flange width and the web width, the effect of longitudinal bowing is decreased. 


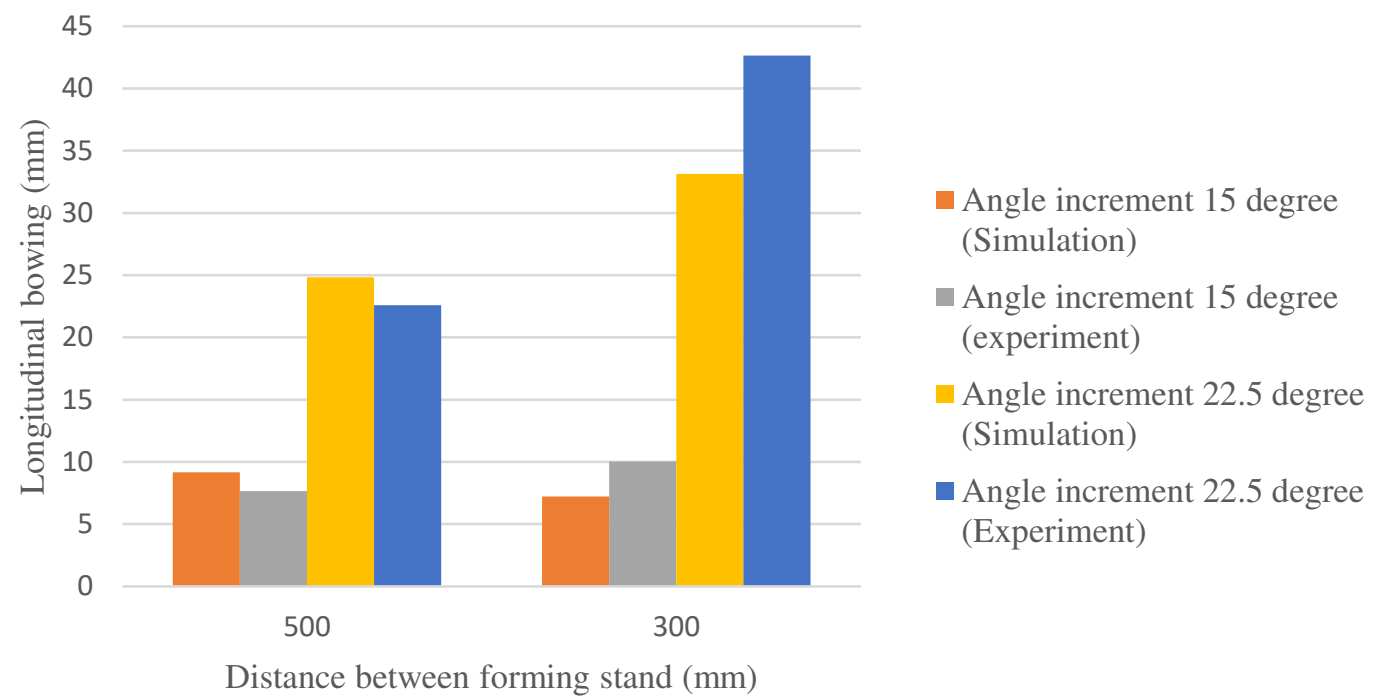

Figure 19 Effect of inter distance on bowing

\subsection{General analysis of factors}

The analytical model is extracted by the experimental results and simulation based on the twolevel model in the design expert software and analyzed based on the factors which are presented in Table 7. Also, the double effects of these factors in the model are analyzed. The R-square is 0.8838 which shows an acceptable accuracy for the model. P-value refers to the effect of each factor on the longitudinal bowing and smaller values of this parameter shows that it has more effect on the longitudinal bowing. Table 7 shows the parameters of the model. Also, the higher value of $\mathrm{R} 2$ and the acceptable error between the actual values and the predicted model prove that an acceptable model is obtained. In this table, C.V. indicates the standard deviation based on the mean value percentage which is presented in Equation 5[24].

$$
\text { C.V. }(\%)=100 \times \frac{\text { Standard deviation }}{\text { Mean }}
$$

Table 7 Accuracy evaluation criteria for the two factor model

\begin{tabular}{|c|c|c|c|c|c|c|c|}
\hline Model & $R^{2}$ & $\begin{array}{c}\boldsymbol{R}^{2} \\
\text { (adjusted) } \\
\end{array}$ & $\begin{array}{c}\boldsymbol{R}^{\mathbf{2}} \\
\text { (predicted) } \\
\end{array}$ & $\begin{array}{l}\text { Standard } \\
\text { deviation }\end{array}$ & Mean & $\begin{array}{l}\text { Adequate } \\
\text { Precision }\end{array}$ & C.V. $(\%)$ \\
\hline $\begin{array}{l}\text { Longitudinal } \\
\text { bowing }\end{array}$ & 0.8838 & 0.8199 & 0.8513 & 3.94 & 11.93 & 15.857 & 33.00 \\
\hline
\end{tabular}

In Figure 20 the Pareto diagram of the parameters on the longitudinal bowing is presented. It can be seen that the strip thickness and plastic anisotropy have the largest and smallest effect on the longitudinal bowing respectively. 


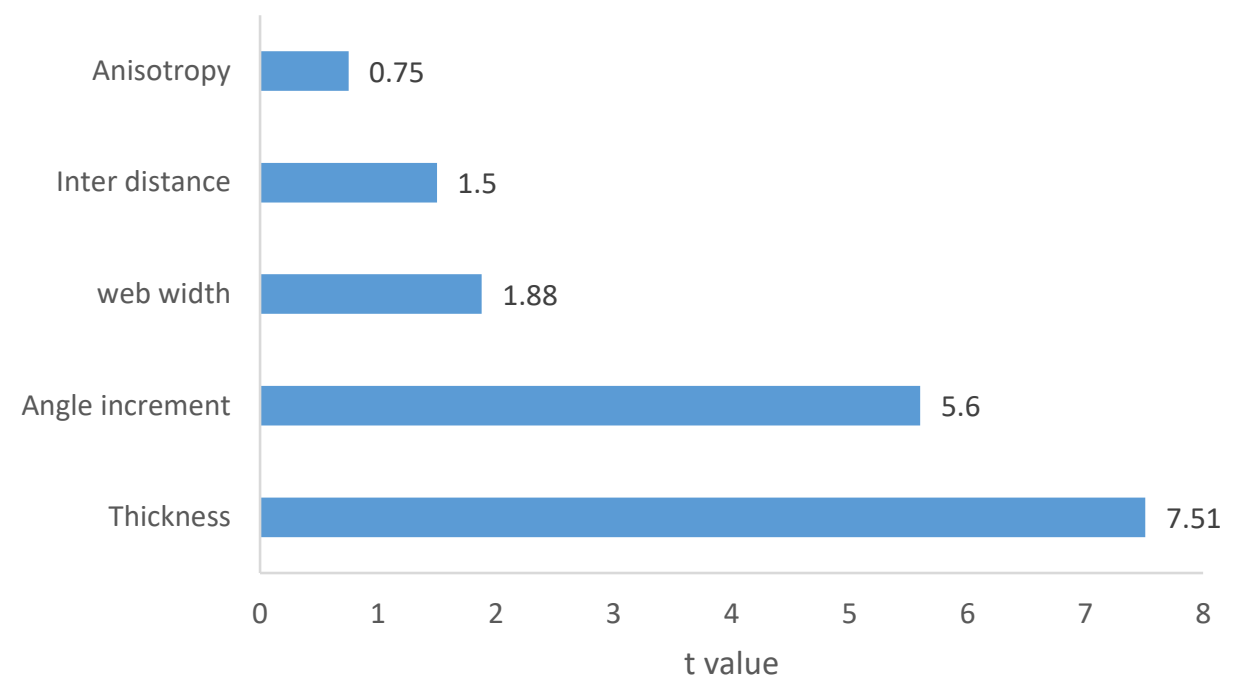

Figure 20 Pareto chart of the standardized effects on bowing

\section{Summary and Conclusion}

In conclusion, based on the presented results, in the cold roll forming process the strip thickness, angle increment, inter distance, web width and the structural anisotropy have these effects:

- The strip thickness is studied as the most important parameter. The longitudinal bowing is increased by the strip thickness. In other words, for a constant bending angle and flange width, an increase in the strip thickness causes a decrease in the required length for the forming process.

- The angle increment influences on the longitudinal bowing as a second important parameter. Decreasing of angle change or increasing of forming stands resulted the reduction of the longitudinal bowing.

- Web width is the third important factor in the longitudinal bowing. As this parameter is decreased, the strain distribution difference between the flange and web of the strip is decreased and it causes a decrease in the longitudinal bowing.

- The inter distance and the plastic anisotropy have small effect on the longitudinal bowing. However, these two parameters together have a significant effect on the longitudinal bowing. But generally, in analyzing the longitudinal bowing, the effects of these two parameters can be neglected.

\section{Acknowledgements}

The cooperation and guidance of PAYA Tubes and Profiles Co. Dr. Hamed Barghikar and the faculty members of the University of Tarbiat Modares are greatly appreciated.

\section{Authors' Information}

Amin Poursafar, born in 1981, is currently a PhD candidate at Islamic Azad university, Najafabad branch, Iran. He received his MSc. degree from The University of Urmia, Iran in 2006. His research interests focus on Metal forming, Machining and Robotics. His email address is amin.poursafar@smc.iaun.ac.ir and Orcid ID is https://orcid.org/0000-0001-87944802. 
Saeid Saberi was born in Isfahan, Iran. He received the $\mathrm{PhD}$ degree in Mechanical engineering from the University of Gratz, Austria, in 2009. He is currently an assistant professor at Islamic Azad university, Najafabad branch, Iran. His research interests include computer vision, nondestructive testing, metal forming, and machining. He is also corresponding author of paper and his email address is saeid_saberi@yahoo.com and his Orcid id is https://orcid.org/00000001-5005-9949.

Rasoul Tarkesh is an assistant professor at Islamic Azad university, Najafabad branch, Iran. His research interests include metal forming, composite materials. His email address is ra tarkesh@pmc.iaun.ac.ir and Orcid ID is https://orcid.org/0000-0001-6434-5794.

Meisam Vahabi is an assistant professor at Islamic Azad university, Najafabad branch, Iran. His research interests include smart material, composite materials, robotics and signal processing. His email address is m.vahabi@pmc.iaun.ac.ir and Orcid ID is https://orcid.org/0000-0002-7864-7993.

Javad Jafari also is an assistant professor at Islamic Azad university, Najafabad branch, Iran. His research interests include metal forming, composite materials and machine vision. jafari@pmc.iaun.ac.ir, https://orcid.org/0000-0003-1701-2350 are his email address and Orcid ID.

Affiliation of all authors is Department of Mechanical Engineering, Najafabad Branch, Islamic Azad University, Najafabad, Iran.

\section{Authors' contributions}

Saeid Saberi was in charge of the whole paper; Amin Poursafar wrote the manuscript and perfected the formulas and programmed the data; Rasoul Tarkesh and Meisam Vahabi and Javad Jafari gave some advices on the manuscript. All authors read and approved the final manuscript.

\section{Availability of data and materials}

The datasets used and analyzed during the current study are available from the corresponding author on reasonable request.

\section{Funding}

Not applicable.

\section{Competing Interests}

The authors declare no competing financial interests.

\section{References}

[1] G.T. Halmos, Roll forming handbook, 2005. https://doi.org/10.1201/9781420030693.

[2] B. Shirani Bidabadi, H. Moslemi Naeini, R. Azizi Tafti, H. Barghikar, Experimental study of bowing defects in pre-notched channel section products in the cold roll forming process, Int. J. Adv. Manuf. Technol. 87 (2016) 997-1011. https://doi.org/10.1007/s00170016-8547-y.

[3] H. Ona, Experiments into the cold roll forming of straight asymmetrical channels, J. Mech. Work. Technol. 8 (1983) 273-291. 
[4] D. Bhattacharyya, P.D. Smith, S.K. Thadakamalla, I.F. Collins, The prediction of roll load in cold roll-forming, J. Mech. Work. Technol. 14 (1987) 363-379. https://doi.org/10.1016/0378-3804(87)90019-2.

[5] D. Bhattacharyya, P.D. Smith, The development of longitudinal strain in cold roll forming and its influence on product straightness.le, Adv. Technol. Plast. 1 (1984) 422-427.

[6] S. Panton, J. Duncan, S. Zhu, Longitudinal and shear strain development in cold roll forming, J. Mater. Process. Technol. 60 (1996) 219-224. https://doi.org/10.1016/09240136(96)02333-3.

[7] J.-J. Sheu, Simulation and optimization of the cold roll-forming process, AIP Conf. Proc. 1 (2004) 452-457. https://doi.org/10.1063/1.1766566.

[8] M.S. Tehrani, P. Hartley, H.M. Naeini, H. Khademizadeh, Localised edge buckling in cold roll-forming of symmetric channel section, Thin-Walled Struct. 44 (2006) 184-196. https://doi.org/10.1016/j.tws.2006.01.008.

[9] B. Shirani Bidabadi, H. Moslemi Naeini, R. Azizi Tafti, S. Mazdak, Experimental investigation of the ovality of holes on pre-notched channel products in the cold roll forming process, J. Mater. Process. Technol. 225 (2015) 213-220. https://doi.org/10.1016/j.jmatprotec.2015.06.008.

[10] B. Shirani Bidabadi, H. Moslemi Naeini, M. Salmani Tehrani, H. Barghikar, Experimental and numerical study of bowing defects in cold roll-formed, U-channel sections, J. Constr. Steel Res. 118 (2016) 243-253. https://doi.org/10.1016/j.jcsr.2015.11.007.

[11] B. Shirani Bidabadi, H. Moslemi Naeini, R. Azizi Tafti, Y. Tajik, Optimization of required torque and energy consumption in the roll forming process, Int. J. Interact. Des. Manuf. 13 (2019) 1029-1048. https://doi.org/10.1007/s12008-019-00564-9.

[12] M. Lindgren, Cold roll forming of a U-channel made of high strength steel, J. Mater. Process. Technol. 186 (2007) 77-81. https://doi.org/10.1016/j.jmatprotec.2006.12.017.

[13] M. Poursina, M. Salmani Tehrani, D. Poursina, Application of BPANN and regression for prediction of bowing defect in roll-forming of symmetric channel section, Int. J. Mater. Form. 1 (2008) 17-20. https://doi.org/10.1007/s12289-008-0057-5.

[14] Q. V. Bui, J.P. Ponthot, Numerical simulation of cold roll-forming processes, J. Mater. Process. Technol. 202 (2008) 275-282. https://doi.org/10.1016/j.jmatprotec.2007.08.073.

[15] M. Lindgren, An improved model for the longitudinal peak strain in the flange of a roll formed U-channel developed by FE-analyses, Steel Res. Int. 78 (2007) 82-87. https://doi.org/10.1002/srin.200705863.

[16] H. wei Zhang, L. zhong Liu, P. Hu, X. hua Liu, Numerical Simulation and Experimental Investigation of Springback in U-Channel Forming of Tailor Rolled Blank, J. Iron Steel Res. Int. 19 (2012) 8-12. https://doi.org/10.1016/S1006-706X(13)60002-3.

[17] V.I. Punin, L.S. Kokhan, Y.A. Morozov, Reduction of the length of strip rolled on rollforming machines, Metallurgist. 56 (2013) 938-940. https://doi.org/10.1007/s11015-0139678-0.

[18] W. gi Cha, N. Kim, Study on twisting and bowing of roll formed products made of high strength steel, Int. J. Precis. Eng. Manuf. 14 (2013) 1527-1533. https://doi.org/10.1007/s12541-013-0206-8.

[19] J.H. Wiebenga, M. Weiss, B. Rolfe, A.H. Van Den Boogaard, Product defect compensation by robust optimization of a cold roll forming process, J. Mater. Process. Technol. 213 (2013) 978-986. https://doi.org/10.1016/j.jmatprotec.2013.01.006.

[20] R. Safdarian, H. Moslemi Naeini, The effects of forming parameters on the cold roll forming of channel section, Thin-Walled Struct. 92 (2015) 130-136. https://doi.org/10.1016/j.tws.2015.03.002. 
[21] R. Hill, E. Orowan, A theory of the yielding and plastic flow of anisotropic metals, Proc. R. Soc. London. Ser. A. Math. Phys. Sci. 193 (1948) 281-297. https://doi.org/10.1098/rspa.1948.0045.

[22] S.J. Mander, S.M. Panton, R.J. Dykes, D. Bhattacharyya, Chapter 12 Roll forming of sheet materials, in: D.B.T.-C.M.S. Bhattacharyya (Ed.), Compos. Sheet Form., Elsevier, 1997: pp. 473-515. https://doi.org/https://doi.org/10.1016/S0927-0108(97)80014-8.

[23] Z.W. Han, C. Liu, W.P. Lu, L.Q. Ren, Simulation of a multi-stand roll-forming process for thick channel section, J. Mater. Process. Technol. 127 (2002) 382-387. https://doi.org/10.1016/S0924-0136(02)00411-9.

[24] K. Hinkelmann, K. Oscar, Design and Analysis of Experiments: Advanced Experimental Design, John Wiley \& Sons, Inc., 2005. https://doi.org/DOI:10.1002/0471709948. 